\title{
The relationship between aesthetic and drawing preferences
}

Article

Accepted Version

Williams, L., McSorley, E. and McCloy, R. (2018) The relationship between aesthetic and drawing preferences. Psychology of Aesthetics, Creativity, and the Arts, 12 (3). pp. 259-271. ISSN 1931-390X doi: https://doi.org/10.1037/aca0000188 Available at https://centaur.reading.ac.uk/78960/

It is advisable to refer to the publisher's version if you intend to cite from the work. See Guidance on citing.

To link to this article DOI: http://dx.doi.org/10.1037/aca0000188

Publisher: American Psychological Association

All outputs in CentAUR are protected by Intellectual Property Rights law, including copyright law. Copyright and IPR is retained by the creators or other copyright holders. Terms and conditions for use of this material are defined in the End User Agreement.

\section{www.reading.ac.uk/centaur}

\section{CentAUR}

Central Archive at the University of Reading 
Reading's research outputs online 
1 Psychology of Aesthetics, Creativity, and the Arts (2018)

2 http://dx.doi.org/10.1037/aca0000188

4 Louis Williams, Eugene McSorley, and Rachel McCloy (University of Reading )

6 There are suggested to be similarities between what is aesthetically preferred and artistically

7 produced; however, little research has been conducted that directly examines this relationship

8 and its links to expertise. Here, we examined the artistic process of artists and non-artists

9 using geometric shapes as stimuli, investigating aesthetic (how pleasing they find the shapes) and drawing preferences (which shape they would prefer to draw out of a choice of two). We examined the cognitive processes behind these preferences using eye-tracking methods both when viewing stimuli and when making drawing preferences. Drawing preference scores increased with increasing aesthetic ratings regardless of expertise. We find gaze behaviour when free-viewing to reflect behaviour when making a drawing preference as both artists and non-artists fixated on aesthetically preferred stimuli first, for longer and more often. Artists gaze behaviour when free-viewing was also influenced by what they would prefer to draw. This suggests that artists have a more fluid relationship than non-artists between images aesthetically preferred and those preferred for drawing. Overall, we demonstrate that there is a relationship between aesthetic preference and artistic preference for production, and this varies with expertise.

22 Keywords: aesthetic preference; drawing preference; eye movements; art expertise 
There is argued to be an interaction between the aesthetic and artistic experiences involved in producing an artwork (Tinio, 2013). The acts of production, perception and enjoyment are suggested to be integrated as the artist behind the artwork conceptualises the artwork and imagines how the perceiver will interact with the final work. The artist visually evaluates their work as a perceiver of the final product in order to create something they believe to be aesthetically pleasing (Dewey, 1934; Zeki \& Nash, 1999). Therefore the cognitive processes involved in the creation of art have been suggested to be similar to the perception of art (Martindale, 2001; Tinio, 2013). Empirical research largely investigates the experience of the perceiver (those perceiving final works of art) with less work examining the experience of the artist. The art-making process arguably differentiates art from other aesthetic forms that can be aesthetically appreciated, such as products and/or objects that are designed. The artist, their behaviour, intentions and actions are important here. Yet less emphasis in current empirical aesthetic research is put on understanding the artist and their aesthetic experience during the art-making process (Tinio, 2013).

One notable attempt to understand the artistic process was put forward by Mace and Ward (2002). They developed an art-making process model from the perspective of the artist. Through interviews with professional artists they aimed to understand the processes of the artist during the creation of their work. They identified four phases. The first phase is artwork conception, which concerns when and how ideas are initially conceived. The second idea development phase follows as an original idea is adapted and modified if necessary. The third stage is the actual production of the artwork. The final stage involves finishing the artwork and evaluating it prior to exhibition. Sapp's (1995) model specifically focuses on the initial stages of art-making and conscious decisions made. Here, they explore the processes of making ideas and identify the importance of making conscious decisions during the production of potential ideas. Specific focus is put on how one idea is selected amongst 
others. Mace \& Ward suggest that these decisions made by artists, including idea selection as presented in Sapp's model, are influenced by the artist's own aesthetic experience demonstrating that there is a relationship between the artists' aesthetic and art-making experience.

\section{Aesthetic and Art-making Experiences}

Initial art-making stages involve making conscious decisions on what to create. Within Sapp's (1995) model for art idea conception it is explained how multiple ideas of a concept are developed and a process of exploring and selecting ideas occurs until one option is selected to be the most significant for a final concept. However, the model does not explore what influences the decisions that are made during these early stages of art-making. Mace and Ward (2002) also present an idea selection stage where a decision is to be made on what to create and they suggest that the artists' aesthetic experiences impact upon decisions made at this stage and indeed at any stage of the art-making process. They further state how engaging in art-making activities can equally influence the artists' personal aesthetic experience. Kay (1991) also suggests that this personal aesthetic experience is used by an artist to construct ideas and aid thought processes when creating art, and that aesthetic preferences, which are part of the overall aesthetic experience and are largely accepted as an outcome of the aesthetic experience (Leder, Belke, Oeberst, \& Augustin, 2004; Tinio, 2013), help guide new art-making and other similar forms of experience. However, no empirical research has directly investigated this relationship. Kozbelt (2017) further addresses how no studies have directly examined how the artists' ideas and development of an artwork is guided by aesthetic characteristics which impact perceiver's aesthetic experiences.

There is some empirical evidence that examines how idea selection takes place, Groenendijk, Janssen, Rijlaarsdam and van den Bergh (2013) used a self-report measure to 
gather information about adolescent students (non-artists) creative drawing activity and found that very little time was spent making a decision on what to create. This may be explained by a lack of expertise leading to a failure to consider alternative ideas, thus one initial idea can quickly and directly become the final artwork (Sapp, 1995). Alternatively it may be because aesthetic preferences are formed in a short period of time that a quick drawing decision can be made (Locher et al., 2007; Willis \& Todorov, 2006). No research to date explores these initial art-making decisions in more depth, however indirect evidence does show some similarities between preference and production which are discussed next.

\section{Aesthetic Preference and Art Production}

Indirect evidence from studies of the content of productions do show similarities between images aesthetically preferred and produced. More complex designs were created and aesthetically preferred by more creative artists, and less complex designs were created and aesthetically preferred by less creative artists (Taylor \& Eisenman, 1964). In addition, images preferred for drawing were found to be dependent on the content of the stimuli to be drawn, despite prior drawing experiences. This could potentially be due to the complexity in producing images, but those images preferred for drawing were also aesthetically preferred (Kozbelt, Seidel, ElBassiouny, Mark \& Owen, 2010; Guggenheim \& Whitfield, 1989). Boyatzis and Eades (1999) consider children's artistic productions, preferences and production choices. They found that the productions created and those selected were influenced by gender stereotypical content, further showing a relationship between preference and production. Furthermore, symmetry has also been found to impact art production with use of symmetry in creations differing dependent on gender and age, however here it has been shown that there tends to be disparities between the types of symmetry preferred and those found in productions (Humphrey, 1997; Washburn \& Humphrey, 2001). So, research 
has reported similarities between preference and production, however there has been no direct exploration of the relationship between preference and production considering those familiar with the art-making process and those with less experience.

\section{Influence of Artistic Expertise}

There is some suggestion that stimuli preferred for creation are similar to those aesthetically preferred and that this varies as a function of expertise. Individuals differ in their knowledge of art and art history, and there are also distinct differences between artists and non-artists regarding aesthetic experiences. Expertise influences general observation of art as more experienced viewers are interested in the work itself but also in the creative process, thus they consider the ideas behind the artwork and desire to understand the process and materials used in order to create the art piece (Pitman \& Hirzy, 2010; Gombrich, 1995). When observing art, gaze patterns have been analysed and differences are apparent due to long term artistic training. Participants untrained in art have been found to focus more on individual elements in a composition. Fixation time towards these elements, for example to human and object features, supports this. More experienced artists however explore the relationships between these elements; they are interested in the global image, overall composition and structural features depicted (Nodine, Locher \& Krupinski, 1993; Pihko et al, 2011; Vogt \& Magnussen, 2007).

Differences due to expertise are also found with regards to the art-making experience. Kozbelt et al., (2010) found artists' drawings to be more accurate than non-artists; artists were found to make better decisions on what features to include in their drawings thus their drawings captured specific features of the face being copied, whereas non-artists drawings were more generic. Artists have been found to possess greater cognitive abilities (perceptual and imagery) when completing drawing tasks where actual production was required, and 
during mental imagery performance (Calabrese \& Marucci, 2006). Expertise has been found to impact artistic creations with artists, not surprisingly, performing better on drawing tasks. In addition to artists having a clear motor advantage, differences are apparent from gaze when drawing. Artists have been found to process stimuli more easily (spend less time fixating the stimulus to be copied) than non-artists regardless of the variations in stimuli (familiarity/complexity) and this is suggested to be due to training (Glazek, 2012).

\section{Gaze: A Tool for Observing Responses to Art and a Measure of Preference}

As can be seen from the preceding section, research examining the eye movements of artists has provided insight into the artistic process. Eye-tracking has also been a useful tool for revealing cognitive processes during the aesthetic experience. Initial eye movement reaction to artworks can be captured using such techniques with responses to art made within $100 \mathrm{~ms}$ being found to correlate with overall aesthetic ratings (Locher et al., 2007). Plumhoff and Schrillo (2009) identified that images rated as pleasing led to greater fixation durations over time than those rated as displeasing. Gaze has also been found to differ when making art. Miall and Tchalenko (2001) studied an artist whilst creating art and recorded his eye movements. Here, they found that the act of painting influenced gaze as fixation durations were twice as long as fixations made when he was not painting. Furthermore, eye-tracking has been recently used as a method for understanding preferences and studies have found gaze to reflect aesthetic preferences and choices when observing multiple images (Shimojo, Simion, Shimojo \& Scheier, 2003; Glaholt, Wu \& Reingold, 2009). Holmes and Zanker (2012) found greater fixation durations and number of fixations to be made to aesthetically preferred stimuli. In addition, free-viewing tasks, which do not provide the participant with specific instruction, have further shown fixation to be influenced by preference with greater fixation being towards faces regarded to be more attractive (Leder, Tinio, Fuchs \& Bohrn, 
2010). Thus eye-tracking is useful for further exploring art-viewing, art-making and decisionmaking, and gaze can be used as a measure of preference.

\section{Summary}

Art-making decisions made by the artist are suggested to be influenced by the artists' aesthetic experience. Idea selection is a testable stage within the art-making process allowing further understanding of these relationships between art-making and aesthetic experiences. Previous research has identified similarities between aesthetic preference, an outcome of aesthetic experiences, and production choice/creation, a process within art-making (Taylor \& Eisenman 1964; Boyatzis \& Eades, 1999). However, here we explicitly examine these relationships; importantly we do this for both non-artists and artists as differences in expertise have been found regarding aesthetic and art-making experiences. Research within the field of empirical aesthetics has begun to adopt more objective methods to explore aesthetic experiences; here we include eye-tracking measures as a useful measure of preference that also allows for further understanding of the formation of aesthetic judgements and has been used in previous research exploring art-making activities.

\section{The Present Study}

Although previous research suggests that there are similarities between artistic production and aesthetic preference, which may be moderated by expertise, there is little research that directly tests these relationships. Here, we seek to examine these relationships in more depth. Using geometric shapes as stimuli, we examine artists and non-artists aesthetic (how pleasing they find the shapes) and drawing preferences (which shape they would prefer to draw out of a choice of two). To provide further insight into the process of forming these preferences we also track eye-movements whilst participants free-view images and make 
their drawing preferences. To be clear, drawing preference is a term we use in relation to the idea selection/drawing decision stage that is depicted in current art-making models. Here, we use a drawing choice task to provide options for the participants to select from and for them to indicate their drawing preferences.

In order to examine the suggested links between aesthetic and drawing preference we use geometric stimuli. Geometric shapes (triangles, diamonds and circles) are common shapes used in drawing tasks and are regularly incorporated into drawings, they are useful to use when understanding relationships between aesthetically preferred stimuli and those preferred for drawing as preferences for shapes can vary largely due to individual differences (Chen et al., 2002; Chen, Tanaka, Matsuyoshi \& Watanabe, 2016). By using geometric stimuli we can provide parameters to control ideas not allowing them to be too broad, but providing stimuli that share similarities yet differ (Sapp, 1995). Use of geometric stimuli also provides novel stimuli reducing the factor of familiarity which can have a great impact on aesthetic preferences and gaze dependent on art expertise of participants (Leder, 2001; Kristjanson, Antes \& Kristjanson, 1989). As previously mentioned, complexity and symmetry can also impact production, and manipulations in complexity and symmetry have been particularly studied to understand aesthetic preferences of geometric and abstract shapes (Chen et al., 2016; Gartus \& Leder, 2013; Reber, Schwarz \& Winkielman, 2004; Taylor \& Eisenman, 1964; Winston \& Cupchik, 1992; McWhinnie, 1971; Jacobsen, Schubotz, Höfel \& Cramon, 2006). Thus geometrical stimuli differing in complexity and symmetry are used here.

We examine whether aesthetic preferences relate to drawing preferences: are those stimuli that are aesthetically preferred also those preferred to be drawn? And is this affected by expertise? Theories suggest relationships between an artists' aesthetic and art-making experience (Mace \& Ward, 2002; Kay, 1991) and some empirical research suggests that there 
are similarities between images aesthetically preferred and produced, yet no direct test of this has been conducted (Taylor \& Eisenman, 1964; Boyatzis \& Eades, 1999). Differences that have been found in responses to art, production preferences and art-making abilities lead us to expect differences in aesthetic and drawing preference relationships dependent on the expertise of the participant. Kay (1991) states how artists' art-making experiences in particular are guided by aesthetic experiences/preferences. Thus, we hypothesise that there will be an association between how pleasing participants, particularly artists, find the geometric images to be and how much they desire to create these.

Theories suggest that similar cognitive processes are involved when making and observing art (Martindale, 2001; Tinio, 2013). We introduce two tasks (Free-viewing and Drawing Choice) where stimuli are freely-viewed and where a drawing preference is made, we examine gaze to further explore the relationships between aesthetic and drawing preference during their formation. Gaze has been used as a measure of preference and it has been previously found that gaze (fixation duration and count) tends to be greater for aesthetically preferred stimuli. However, it is not clear how aesthetic preferences relate to gaze when freely viewing images, and as we explore the aesthetic and drawing preference relationship it is interesting to examine if similar findings are found in relation to images that are preferred for drawing (Holmes \& Zanker, 2012; Leder, Tinio, Fuchs \& Bohrn, 2010). When drawing preferences are made then gaze is expected to be directed by choice, thus by images preferred for drawing (Shimojo, Simion, Shimojo \& Scheier, 2003; Glaholt, Wu \& Reingold, 2009). If aesthetic preference relates to drawing preference as suggested, then images aesthetically preferred should also influence gaze in a similar manner. How gaze is directed during a Free-viewing and Drawing Choice task is likely to differ dependent on expertise. Artists have been found to process artworks differently to non-artists when observing and creating art, in fact they are more likely to consider the artistic process during 

mere observation (Pihko et al, 2011; Glazek, 2012; Pitman \& Hirzy, 2010; Kozbelt, 2001).

224 Thus, we hypothesize that similar gaze behaviour will be made during the Free-viewing and 225 Drawing Choice task as we expect similar relationships between images aesthetically 226 preferred and those preferred for drawing with gaze (first saccade latency, first fixation 227 direction, fixation duration, fixation count, last fixation duration, and last fixation direction).

228 This would be particularly so for artists. In addition, we hypothesise that this relationship will 229 be more prominent the more an image is aesthetically preferred and preferred for drawing. 


\section{Method}

231

232

233

234

236

237

238

239

240

241

242

243

244

245

246

247

248

\section{Participants}

A total of forty participants took part in this study. Twenty psychology students were recruited from the University of Reading and were regarded as non-artists (11 females, 9 males; range 19-42). Twenty student artists (16 females, 4 males; range 20-35) were recruited from the Fine Art department at the University of Reading. Participants were classified on the basis of a background questionnaire. The questionnaire requested the participant to provide the number of years of formal art training (A-level qualification and beyond) they had received. A participant was regarded as an artist if they had at least 5 years of formal art training and were involved in art-making on a weekly basis. Artists ranged from 5 to 7 years with a mean of 5.6 years of training. The non-artists in this study had less than 1 year with a mean of 0.05 years of training. All participants had normal or corrected-to-normal vision and each stage of the study was completed by all participants.

\section{Materials}

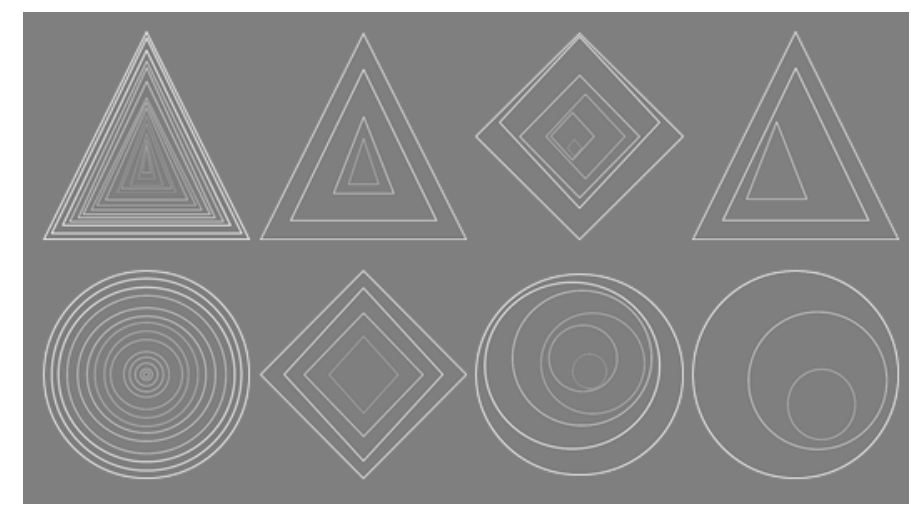

Figure 1. Examples of stimuli used in four subsets. Column one: complex-symmetrical (subset 1); Column two: simple-symmetrical (subset 2); Column three: complex-asymmetrical (subset 3); Column four: simpleasymmetrical (subset 4). 
The stimuli included 8 computer-generated geometric shapes that were fully constructed of triangles, diamonds or circles (see figure 1). Geometric stimuli provide the participant with potential ideas that do not give too much detail of a final product (i.e. colour and texture) which will not be available at such early stages of art-making. Both complexity and symmetry are manipulated here in order to evoke differences in aesthetic response not as primary experimental dimensions of interest in their own right (Eisenman, 1968; Eisenman \& Gellens, 1968; Tinio \& Leder, 2009).

The stimuli differed in terms of symmetry and complexity, this was confirmed by piloting images beforehand requesting participants (who were not involved in the current study) to rate images on a level of complexity [1(very simple) to 7 (very complex)], and whether they contained at least one line of symmetry. 8 images were selected and were grouped into four subsets based on these ratings, each containing two images; [complexsymmetrical (subset 1), simple-symmetrical (subset 2), complex-asymmetrical (subset 3) and simple-asymmetrical (subset 4)].

Pleasingness Scale. A 7-point scale measuring pleasingness was used to gather aesthetic ratings [1(very displeasing) to 7 (very pleasing)] (Russell \& George, 1990).

Drawing Preference Scale. A drawing choice task presented participants' with multiple options from which they could select the image they preferred to draw. Participants were requested to make a selection by indicating how much they preferred to draw the image using a relative preference scale. This scale was used to categorise drawing responses [1 (indicating a strong preference for the left image) to 7 (a strong preference for the right)]. Relative preference towards the two images was calculated by a key press of numbers 1-3 indicating a preference for the left image or 5-7 for the right image (the more extreme values represent a stronger preference), with 4 representing no preference (Park, Shimojo \& Shimojo, 2010). 
This scale provided drawing preference scores for each image from one response and provided detail on how much more the participants wanted to draw one image over another.

\section{Apparatus}

Stimuli were presented on a 21 " colour desktop PC that had a refresh rate of $75 \mathrm{~Hz}$. The distance between the monitor and participant was $57 \mathrm{~cm}$. All images were presented on a grey background and sized to $480 \times 480$ pixels. Stimulus width and height subtended $11.9^{\circ}$ and $11.9^{\circ}$ of visual angle. Eye movements of the right eye were recorded using an Eyelink II tracker with a sampling rate of $500 \mathrm{~Hz}$. A chin rest was used to constrain head movements and participants were placed in a set position. At the beginning of each eye-tracking task a standard 9-point grid was used to calibrate eye movements. All participants calibrated successfully (average error less than $0.5 \mathrm{deg}$ ). Calibration was maintained for each trial using a drift correct procedure between each trial that corrected fixation errors due to small movements in camera alignment (e.g. caused by head band slippage).

\section{Procedure}

A repeated measures design was used; all participants completed all sections of the experiment. Initially participants read the instructions provided and completed a consent form. At the end of the study participants were provided with a debrief form

Aesthetic Rating Task. Half of the participants gave aesthetic ratings for all images prior to the eye-tracking tasks (Free-viewing \& Drawing Choice) while the remaining completed this at the end of the study. All images were presented for 5000ms prior to making an aesthetic judgement. 
Free-viewing Task. 24 possible image pair combinations were viewed whilst eye

297 movements were recorded and were randomised for all participants. For the free-viewing task a fixation cross was displayed before each trial for $1000 \mathrm{~ms}$ then participants were presented with two images for 5000ms (see figure 2). 48 trials were completed at random (all stimuli combinations were presented twice allowing each image in a pair to be presented on either side of the screen); no further information was provided for this task. The Free-viewing task was always completed prior to the Drawing Choice task to avoid bias, and eye-movements were recorded during both tasks.

Drawing Choice Task. Participants then completed a Drawing Choice task during which eye movements were recorded whilst participants made a preference on which image of two they would prefer to draw (see figure 2). 24 possible image pair combinations were viewed; this order was randomised for each participant. A fixation cross was first displayed for $1000 \mathrm{~ms}$; images were then presented until a preference was made as no time limit was imposed. 96 trials were completed at random (all stimuli combinations were presented four times allowing each image in a pair to be presented on either side of the screen twice). Here, more trials were incorporated as it was expected that the drawing preference scores would be less stable (for example, due to naïve participants' lack of familiarity with making this drawing preference judgement rather than a more common aesthetic preference judgement). We measured drawing preference using a relative preference scale to gather responses on what participants would choose to create and how much they preferred to create this compared to the other image displayed. 


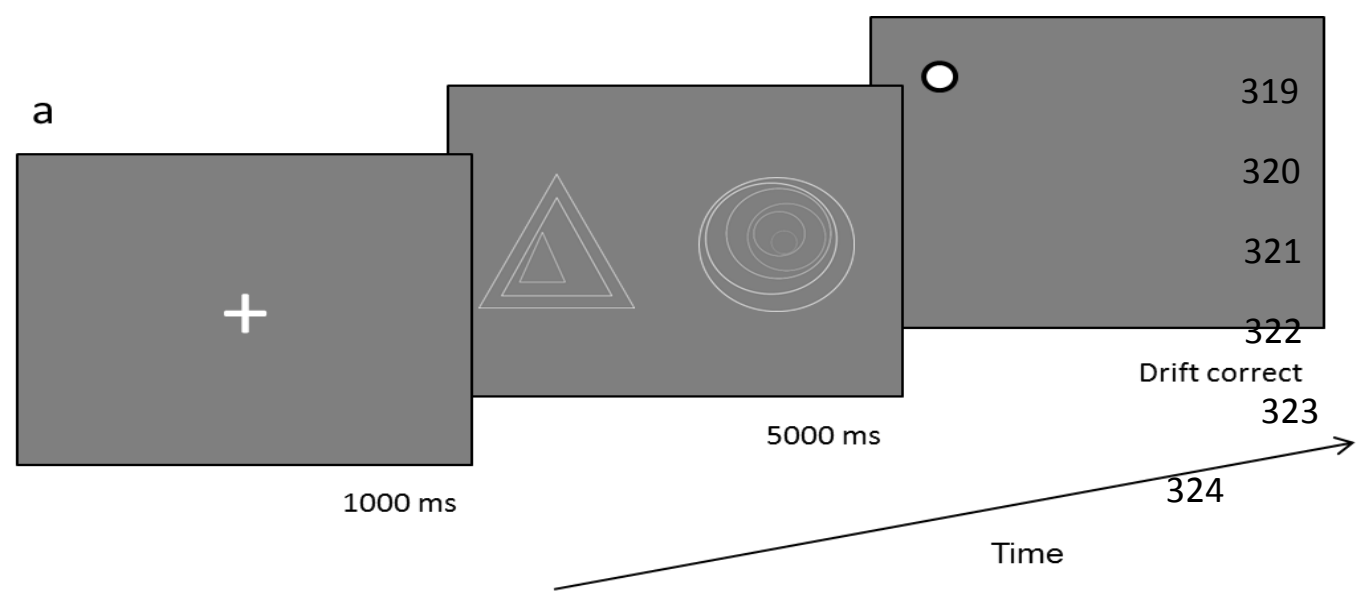

326

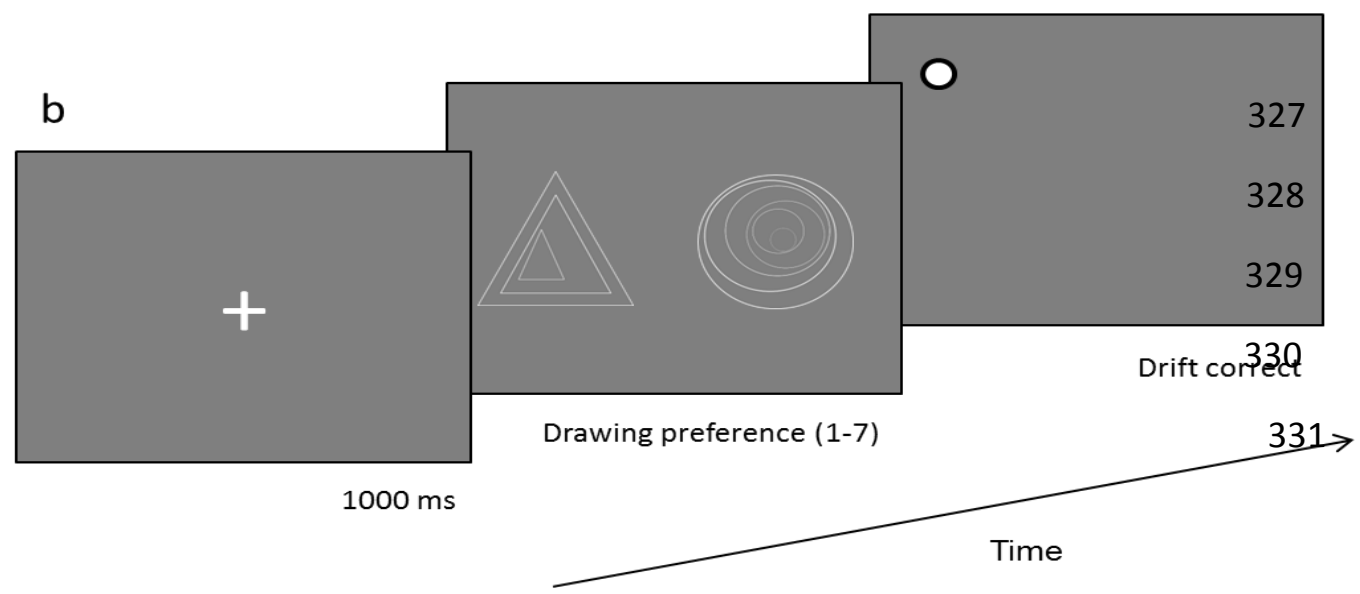

Figure 2. Free-viewing (a) and Drawing Choice (b) task trial examples

\section{Eye-tracking Analyses}

A variety of gaze metrics were used including first fixation direction (to the left or right stimulus), first saccade latency (the response time from stimuli onset to the start of the first saccadic eye movement response), total fixation duration (the total amount of time spent on each stimulus), and number of fixations (the total number of fixations on each stimulus).

341 In addition, for the Drawing Choice task in which a choice between stimuli is made, the last

342 fixation position (image that was being fixated when choice was made) and last fixation 343 duration (how long the last image was fixated as choice is made) were also reported. Such gaze metrics are useful to examine and have been analysed in past research (Holmes \& 
Zanker, 2012). Fixations were classified as such if they exceeded 100ms; if fixation along the $\mathrm{x}$-axis was less than 800 pixels then this was regarded as fixation to the left image, if greater than 800 pixels, then fixation was to the right image.

\section{Data Analyses}

Repeated Measures ANOVA. Two-way repeated measures ANOVAs were run to examine which images were fixated on more due to aesthetic and drawing preference. Each trial of both the Free-view and Drawing Choice tasks was categorised and the aforementioned gaze responses derived on the basis of the aesthetic rating that participant gave for each image, e.g., the duration and number of fixations made on the most preferred image and the duration and number of fixations on the least preferred image on each trial (answering the question of whether gaze behaviour relates to the images aesthetically preferred). The same trials from both tasks were then reclassified on the basis of the drawing preference score given for each image (answering the question of whether gaze behaviour relates to the images preferred for drawing). Note that trials in which there was no preference found between the images were removed.

Multi-level Model Analyses. Mixed-effect models were conducted using multi-level modelling, using the function "lmer" in the "lme4" package for the statistical program R (Bates, Maechler \& Walker, 2013). Multi-level modelling considers that there is unexplained variability in all levels (Snijders \& Bosker, 2012). Random intercepts for participant were included to take into account the variability due to differences between participants. The random intercept of image takes into account the variation caused by differences between images observed.

Aesthetic and drawing preference. Aesthetic ratings of each image were recorded and a drawing preference score for each image was calculated across the trials. We investigated 
whether aesthetic preference associated with drawing preference. A mixed-effects model was conducted with drawing preference as the dependent variable. Aesthetic preference and expertise were included as fixed variables. We used a within-subject mean centering approach.

Proportion of fixation on aesthetic and drawing relative preference. Mixed-effects models were also conducted with proportion of fixation on preference (aesthetic or drawing) as the dependent variable. The difference between ratings (aesthetic and drawing preference) and expertise were included as fixed variables. We used a within-subject mean centering approach. We investigated whether proportion of fixation towards preference (aesthetic or drawing) associated with the difference between ratings (aesthetic or drawing preference). In order to run this analysis, the differences in ratings (aesthetic or drawing preference) given to each image on each trial and the proportion of time spent fixating each image was calculated. 
We first report mixed-effects models examining the association between aesthetic and drawing preference (see Aesthetic and Drawing Preference Relationship Section). Gaze behaviour during Free-viewing is then reported. Trials are classified first by aesthetic preference (Free-viewing and Aesthetic Preference) and then by drawing preference (Freeviewing and Drawing Preference) for artists and non-artists. Finally, we report gaze behaviour elicited during the Drawing Choice task in the same manner as the Free-viewing task: trials classified first by aesthetic preference (Drawing Choice and Aesthetic Preference) and then by drawing preference (Drawing Choice and Drawing Preference). In the sections where gaze is reported, we also present mixed-effects models for the proportion of fixation made towards preferences (aesthetic or drawing) dependent on differences between ratings (aesthetic or drawing preference).

Aesthetic and Drawing Preference Relationship

A mixed-effects model was conducted to investigate whether aesthetic preference associated with drawing preference. Drawing preference scores increased with increasing aesthetic ratings $(\beta=0.869, \mathrm{SE}=0.0972, \mathrm{t}=8.940, \mathrm{p}<0.001)$. There was no significant effect of expertise $(\beta<0.001, \mathrm{SE}=0.127, \mathrm{t}<0.001, \mathrm{p}=1.000)$ nor was there an interaction between expertise and aesthetic ratings $(\beta<0.001, \mathrm{SE}=0.0 .138, \mathrm{t}=0.003, \mathrm{p}=0.998)$. 
Free-viewing and Aesthetic Preference
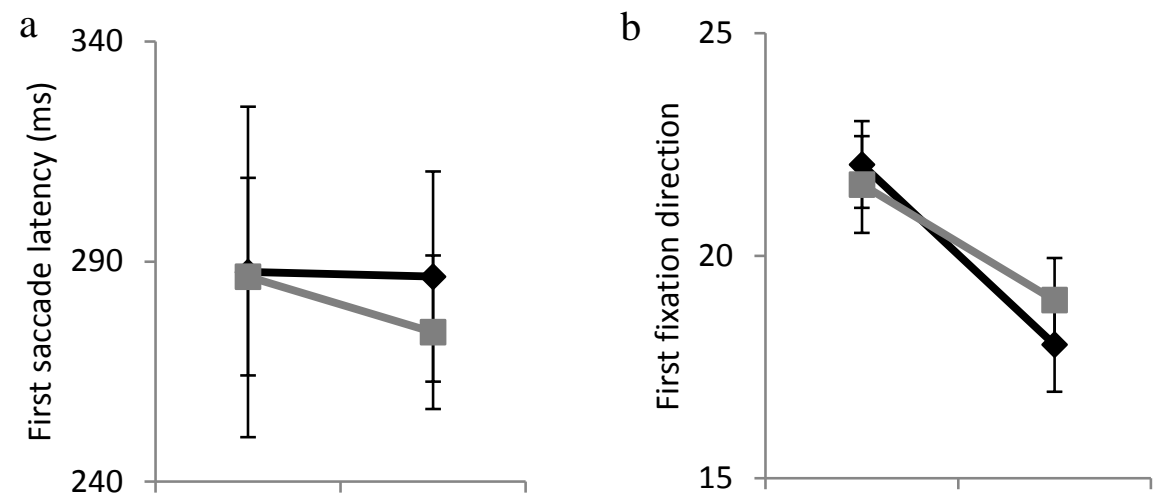

405

406

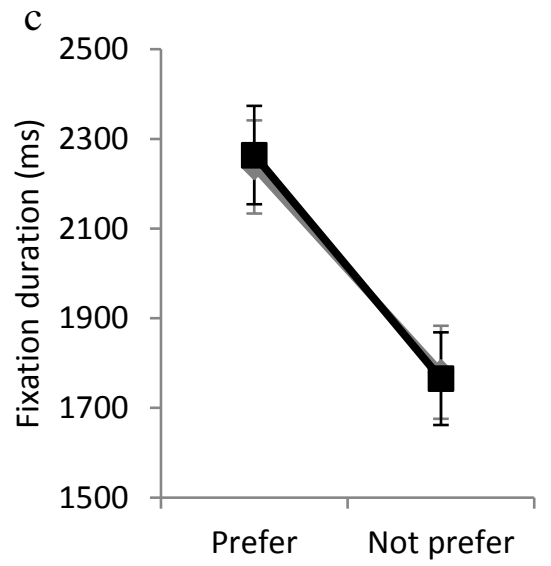

d

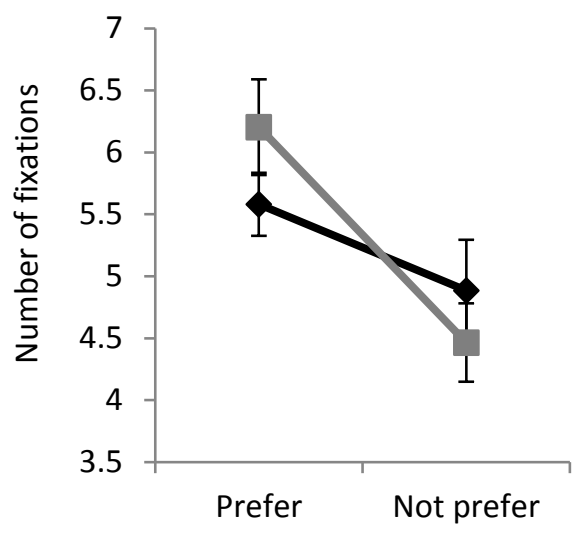

407

Figure 3. Free-viewing task (Aesthetic Preference). Shows gaze behaviour when image pairs are classified on the basis of aesthetic preference: gaze on the aesthetically preferred stimulus and that on the non-preferred stimulus. Upper row shows first saccade response: the latency of the response in milliseconds (Left) and its direction (Right). Lower row shows overall fixation behaviour: mean total fixation duration in milliseconds (Left) and the mean number of fixations (Right).

Figure 3 shows gaze behaviour elicited during the Free-viewing task when images are classified by aesthetic preference. A two-way ANOVA was conducted examining first saccade latency (fig. 3a) with aesthetic preference and expertise as factors. No main effects or 416 interactions were found, all $p$ 's $>$.737. A series of two-way ANOVAs with the same factors 417 were conducted examining first fixation direction (fig. 3b), fixation duration (fig. 3c) and number of fixations (fig. 3d). An effect of aesthetic preference was found with participants 
419 fixating more on preferred stimuli: First Fixation Direction: $F(1,38)=7.097, M S E=31.1155$

$420 p=0.011, \eta^{2}=0.157$; Fixation Duration: $F(1,38)=17.092, M S E=411278.275, p<0.001, \eta^{2}$

$421=0.310 ;$ Number of Fixations: $F(1,38)=12.717, \quad M S E=2.329, \quad p<0.001, \quad \eta^{2}=0.251$, 422 respectively. There was no main effect of expertise and no significant interaction, all $423 p$ 's $>0.135$.

425 Aesthetic Ratings. A mixed-effects model was conducted to investigate whether the 426 proportion of fixation towards aesthetic preferences associated with the differences in 427 aesthetic ratings. The proportion of fixation spent on the aesthetically preferred image 428 increased with an increased difference in aesthetic ratings $(\beta=0.033, \mathrm{SE}=0.008, \mathrm{t}=3.939$, $429 \mathrm{p}<0.001)$. There was no effect of expertise $(\beta=-0.041, \mathrm{SE}=0.036, \mathrm{t}=-1.138, \mathrm{p}=0.263)$. There 430 was no interaction between the fixed effects $(\beta=-0.01, \mathrm{SE}=0.012, \mathrm{t}=-0.801, \mathrm{p}=0.423)$. 
Free-viewing and Drawing Preference
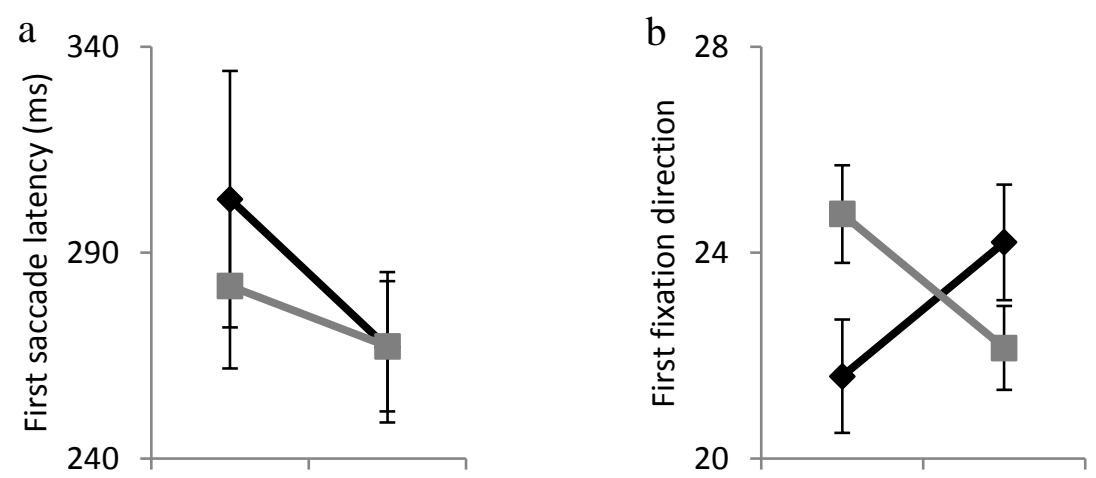

433
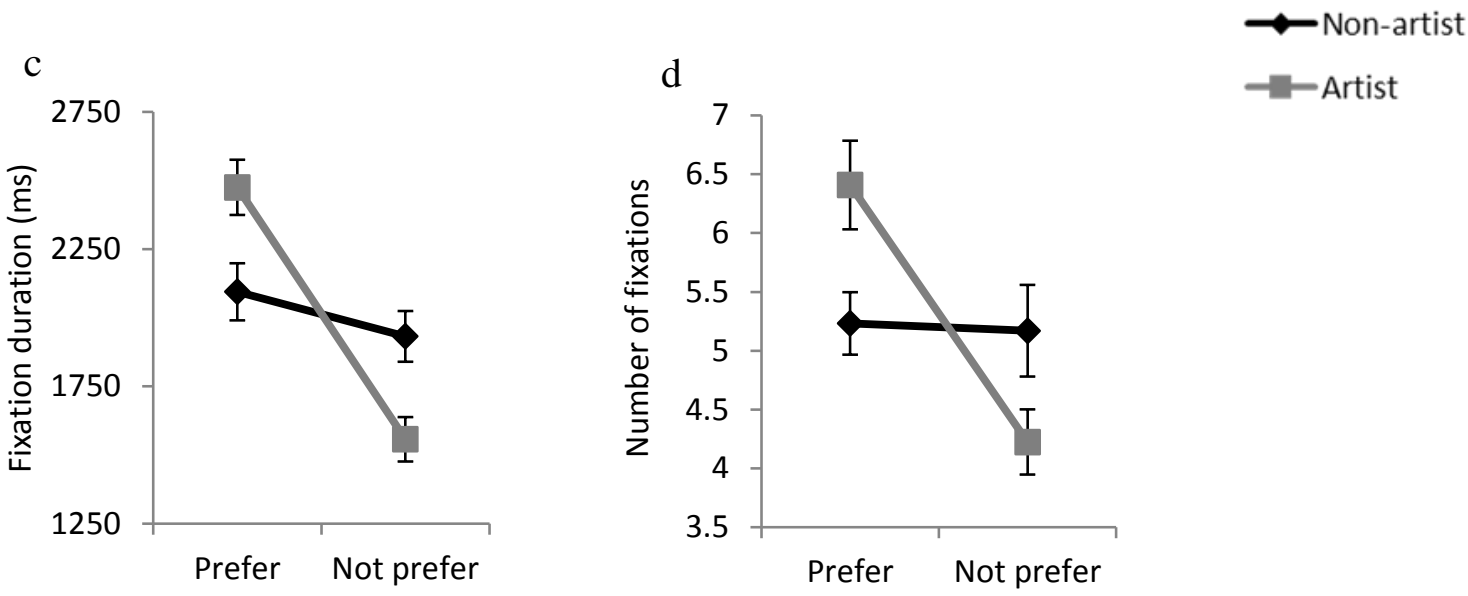

434

Figure 4. Free-viewing task (Drawing Preference) shows gaze behaviour when image pairs are classified on the basis of drawing preference: gaze on the image that is preferred for drawing and that on the non-preferred. Organisation of figures corresponds with figure 3.

Figure 4 shows gaze behaviour elicited during the Free-viewing task when images are classified by drawing preference. A two-way ANOVA was conducted examining first saccade latency with drawing preference and expertise as factors. First saccade latency (fig. 4a) was found to be quicker towards stimuli less preferred for drawing $(M=267.15)$ than preferred $(M=292.44), F(1,38)=4.592, M S E=2785.269, p=0.039, \eta^{2}=0.108$, there was no main effect of expertise or any significant interactions, all $p$ 's $>.371$. A two-way ANOVA was conducted examining first fixation direction with the same factors (fig. 4b), this showed no main effects, all $p$ 's $>.101$, but did show a marginal interaction between drawing preference 
447 and expertise $F(1,38)=3.536, M S E=135.2, p=0.068, \eta^{2}=0.085$. Pairwise comparisons show 448 that artists made more first fixations $(M=24.75)$ to images preferred for drawing compared to non-artists $(M=21.6), F(1,38)=4.698, M S E=99.225, p=0.037, \eta^{2}=0.110$. Further two-way ANOVAs examining fixation duration (fig. 4c) and then number of fixations (fig. 4d) showed only an effect of drawing preference with participants fixating for longer and more often on the stimulus they preferred to draw: Fixation Duration $F(1,38)=17.765, M S E=328432.033$, $p<0.001, \eta^{2}=0.319 ;$ Number of Fixations: $F(1,38)=12.724, M S E=1.979, p<0.001, \quad \eta^{2}$ $=0.251$. There was no effect of expertise, all $p$ 's $>0.744$; however, an interaction between drawing preference and expertise for both fixation duration and number of fixation metrics was found, $F(1,38)=8.688, p<0.001, \eta^{2}=0.186 ; \quad F(1,38)=11.403, p=0.002, \quad \eta^{2}=0.231$, respectively. Pairwise comparisons show that only artists fixated significantly longer on images preferred for drawing $(M=2475.2)$ than less preferred images $(M=1557.4), F(1$, $38)=25.650, p<0.001, \eta^{2}=0.403$, and made more fixations to images preferred for drawing

$(M=6.4)$ than those less preferred $(M=4.2), F(1,38)=24.108, p<0.001, \eta^{2}=0.388$.

Drawing Preference Scores. Further multi-level model analyses were conducted to examine

if the proportion of fixation to drawing preferences associated with the differences in drawing preference scores. The proportion of fixation spent on the image preferred for drawing increased as the differences in drawing preference scores increased $(\beta=0.042, \mathrm{SE}=0.008, \mathrm{t}=$ 5.364, $\mathrm{p}<0.001)$. There was an effect of expertise $(\beta=-0.093, \mathrm{SE}=0.031, \mathrm{t}=-2.984, \mathrm{p}<0.01)$ which suggests that the proportion of fixation to drawing preference was greater for artists $(M=0.612)$ compared to non-artists $(M=0.519)$. However, no interaction was found between expertise and difference in scores $(\beta=-0.019, \mathrm{SE}=0.011, \mathrm{t}=-1.673, \mathrm{p}=0.095)$, 
Drawing Choice and Aesthetic Preference

472
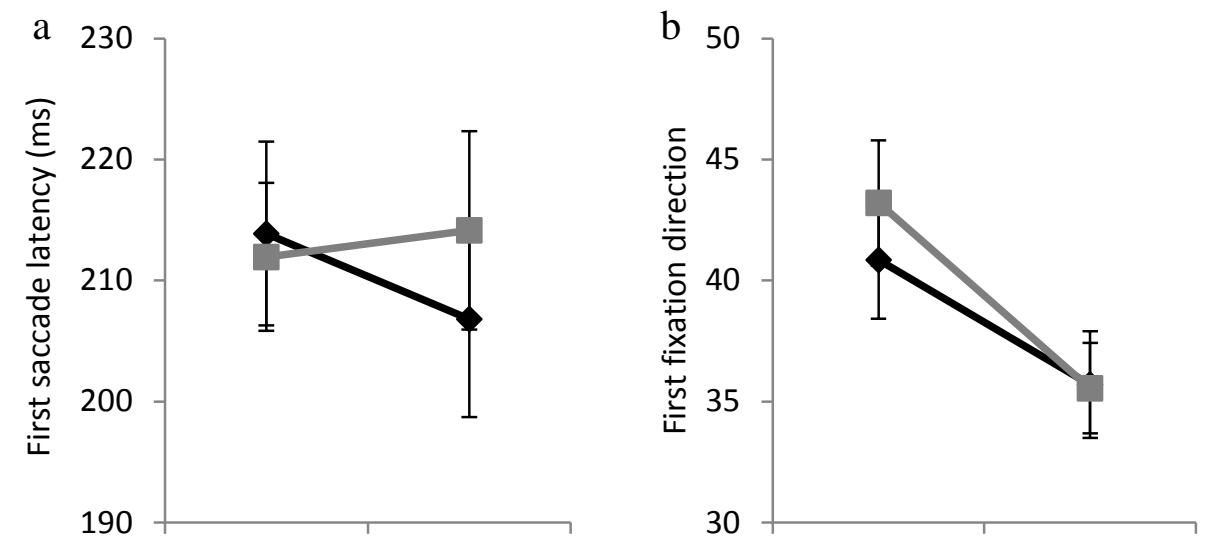

C

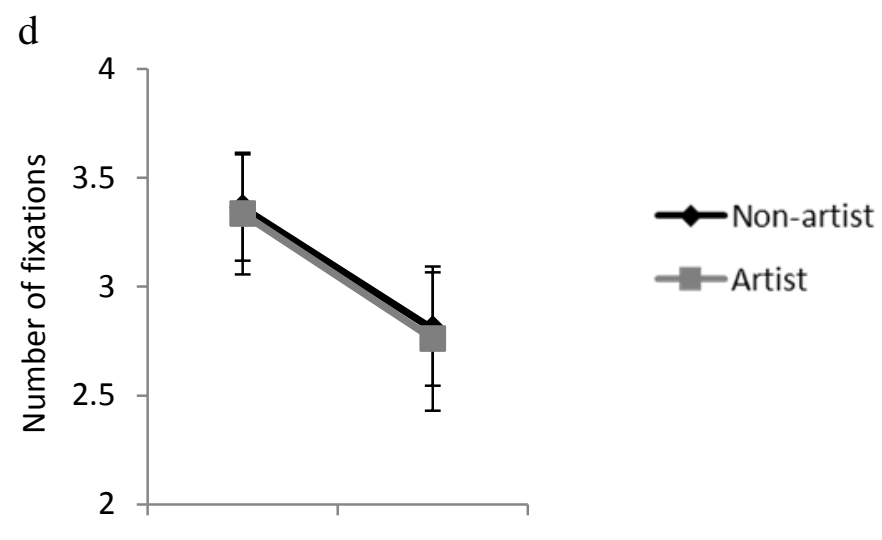

473
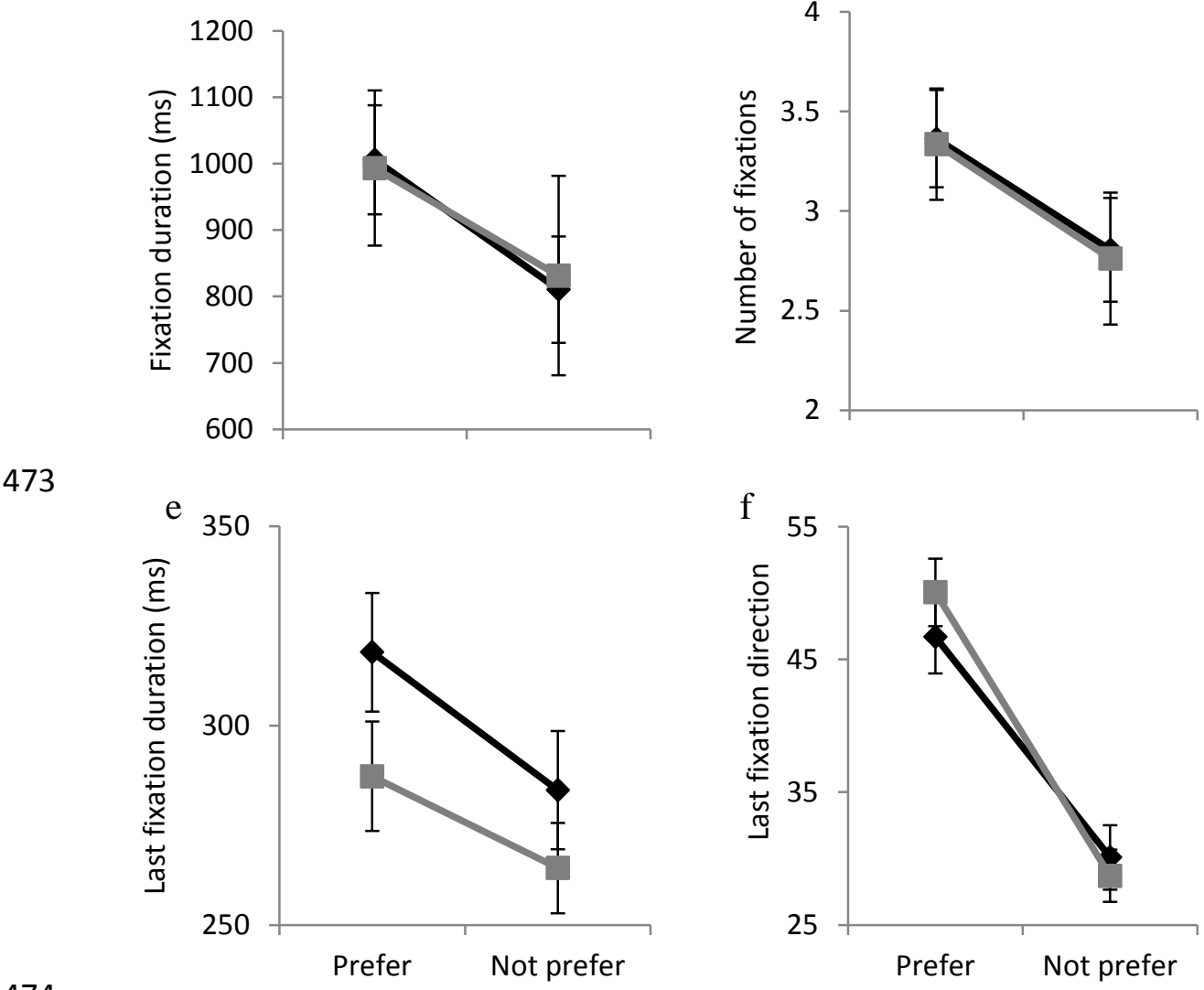

475 Figure 5. Drawing Choice task (Aesthetic Preference): shows gaze behaviour when image pairs are classified 476 on the basis of aesthetic preference: gaze on the image that was aesthetically preferred and that on the non-

477 preferred image. Upper row shows first saccade response: the latency of the response in milliseconds (Left) and 478 its direction (Right). Middle row shows overall fixation behaviour: mean total fixation duration in milliseconds 479 (Left) and the mean number of fixations (Right). Lower row shows last fixation behaviour: last fixation duration 480 (Left) and its direction (Right). 
482

483

484

485

486

487

488

489

490

491

492

493

494

495

496

497

498

499

500

501

502

task. Here, we move on to the results from the Drawing choice task. The same data analysis approach will be taken. Figure 5 shows gaze behaviour elicited during the Drawing Choice task when images are classified by aesthetic preference. A series of separate two-way ANOVAs were conducted, for each dependent variable. No main effects or interactions of aesthetic preference and expertise were found for first saccade latency (fig. 5a), all $p$ 's $>.329$. A main effect of aesthetic preference was found with participants fixating more on stimuli they aesthetically preferred for first fixation direction (fig. 5b) $F(1,38)=7.872$, $M S E=104.067, \quad p=0.008, \quad \eta^{2}=0.172$, fixation duration (fig. 5c) $F(1, \quad 38)=21.002$, $M S E=30436.297, p<0.001, \eta^{2}=0.356$, number of fixations (fig. 5d) $F(1,38)=24.995$, $M S E=0.256, p<0.001, \eta^{2}=0.397$, last fixation duration (fig. 5e) $F(1,38)=10.381$, $M S E=1600.295, p=0.003, \eta^{2}=0.215$, and last fixation direction (fig. $5 f$ ) $F(1,38)=51.160$, $M S E=140.755, p<0.001, \eta^{2}=0.574$. No effect of expertise or interactions were found, all $p ' s>0.376$.

\section{Proportion of Fixation Towards Aesthetic Preference and Differences Between}

Aesthetic Ratings. A mixed-effect model was conducted to examine if the proportion of fixation to aesthetic preferences associated with the differences in aesthetic ratings. The proportion of fixation spent on the image aesthetically preferred increased as the differences in aesthetic ratings increased $(\beta=0.03, \mathrm{SE}=0.005, \mathrm{t}=5.502, \mathrm{p}<0.001)$. No effect of expertise was found and there was no interaction $(\beta=0.007, \mathrm{SE}=0.026, \mathrm{t}=0.276, \mathrm{p}=0.784 ; \beta=-0.002$, $\mathrm{SE}=0.008, \mathrm{t}=-0.273, \mathrm{p}=0.785)$. 
Drawing Choice and Drawing Preference

504
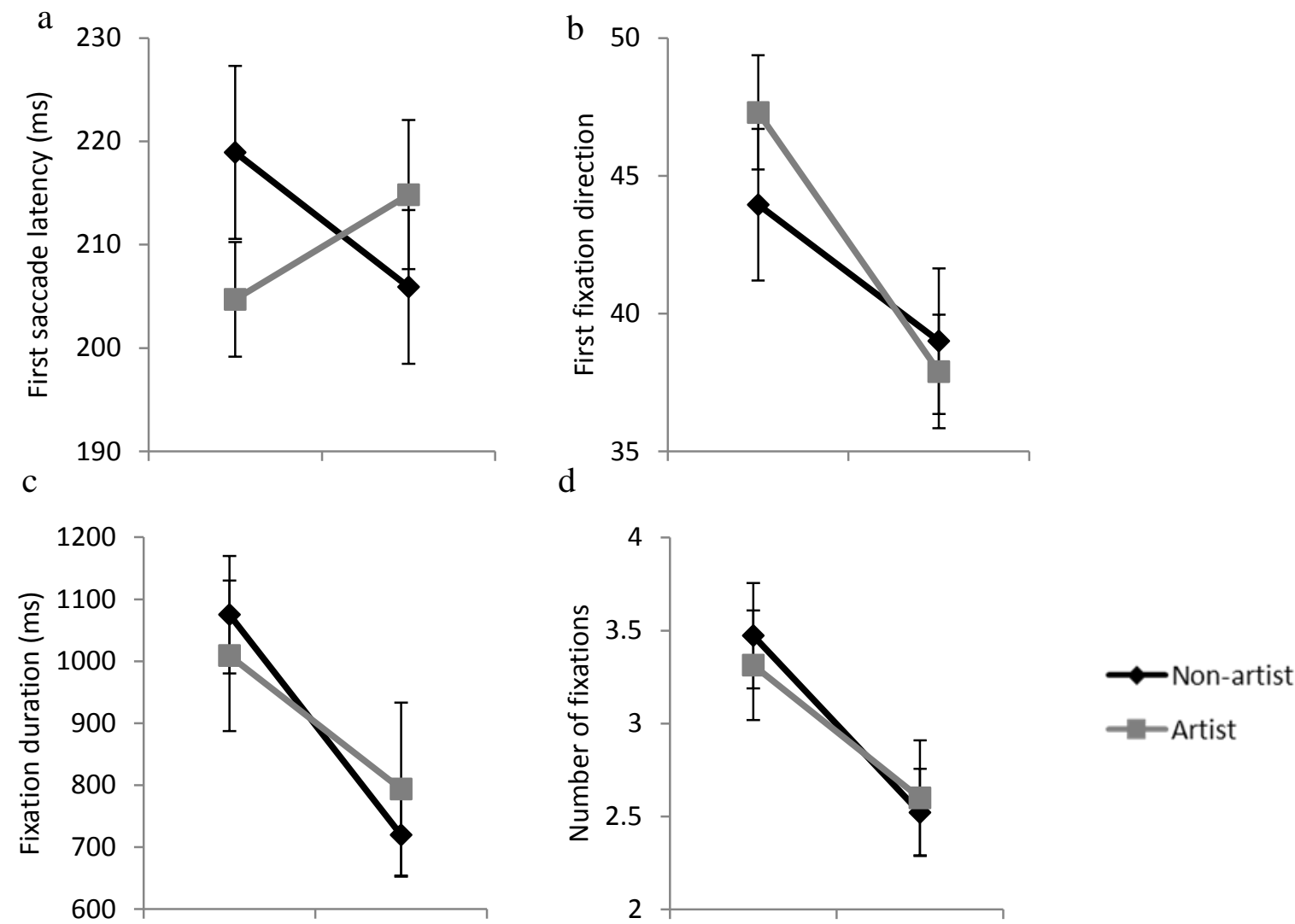

505

e

\section{f}
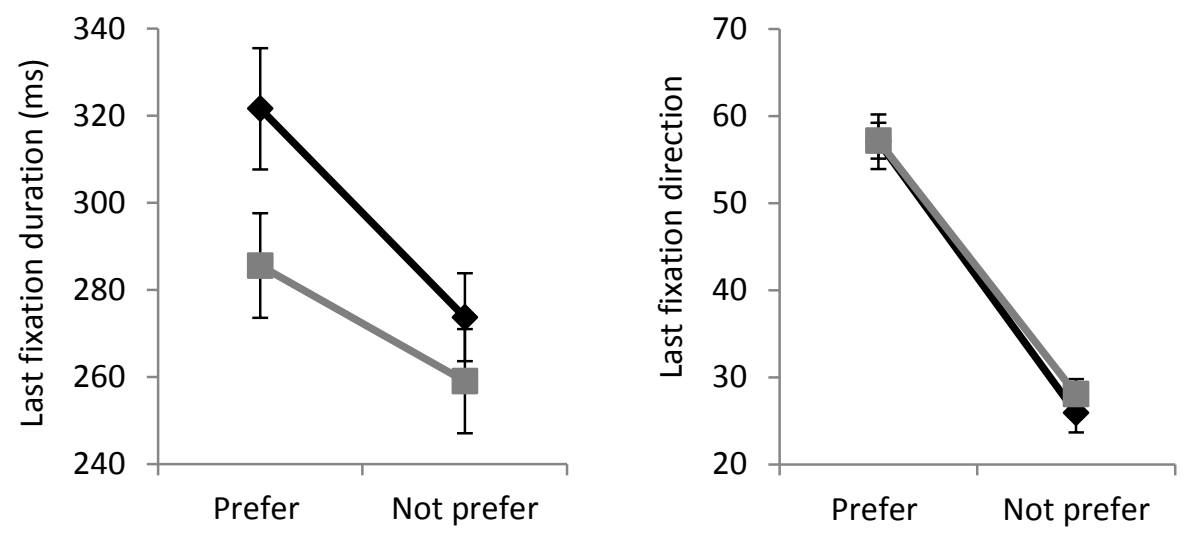

506

Figure 6. Drawing Choice task (Drawing Preference): shows gaze behaviour when image pairs are classified on

508 the basis of drawing preference: gaze on the image that is preferred for drawing and that on the non-preferred. Organisation of figures corresponds with figure 5.

Figure 6 shows gaze behaviour elicited during the Drawing Choice task when images

511 are classified by drawing preference. First saccade latency behaviour was examined as a

512 function of aesthetic preference and expertise. A two-way ANOVA showed no main effects, 
513

514

515

516

517

518

519

520

521

522

523

524

525

526

527

528

529

530

531

532

533

534

535

all $p$ 's $>.666$, but did show an interaction between expertise and drawing preference, $F(1$, 38)=12.152, $M S E=2679.466, p<0.001, \eta^{2}=0.242$ which shows that artists' first saccade latency (fig. 6a) was quicker to images preferred for drawing $(M=204.7)$ than those not preferred $(M=214.8), F(1,38)=4.654, p=0.037, \eta^{2}=0.109$. Whereas non-artists first saccade latency was quicker to images not preferred for drawing $(M=205.9)$ than those preferred $(M=218.9), F(1,38)=7.687, p=0.009, \eta^{2}=0.168$. Similarly to previous sections, a series of separate two-way ANOVAs were conducted for first fixation direction, fixation duration, number of fixations, last fixation duration and direction with preference and expertise as factors. A main effect of drawing preference was found with participants fixating more on those stimuli they would prefer to draw for first fixation direction (fig. $6 b$ ) $F(1,38)=6.909$, $M S E=149.023, p=0.012, \eta^{2}=0.154$, fixation duration (fig. 6c) $\quad F(1,38)=53.844, M S E=$ 30221.218, $\mathrm{p}<0.001, \eta^{2}=0.586$, number of fixations (fig. $6 \mathrm{~d}$ ) $F(1,38)=63.458, M S E=0.218$, $p<0.001, \eta^{2}=0.625$, last fixation duration (fig. 6e) $F(1,38)=22.998, M S E=1204.925, p<0.01$, $\eta^{2}=0.377$ and last fixation direction (fig. 6f) $F(1,38)=130.327, M S E=139.268, p<0.001, \eta^{2}$ $=0.774$. No effect of expertise or interactions were found, all $p$ 's $>0.176$.

\section{Proportion of Fixation Towards Drawing Preference and Differences Between}

Drawing Preference Scores. Multi-level models were carried out to examine if the proportion of fixation to drawing preferences associated with the differences in drawing preference scores. The proportion of fixation spent on the image preferred for drawing increased with increasing differences in drawing preference scores $(\beta=0.025, \mathrm{SE}=0.005, \mathrm{t}=$ $4.915, \mathrm{p}<0.001)$. There was no effect of expertise, nor was there an interaction $(\beta=0.025, \mathrm{SE}=$ $0.022, \mathrm{t}=1.143, \mathrm{p}=0.260 ; \beta=-0.00002, \mathrm{SE}=0.007, \mathrm{t}=-0.003, \mathrm{p}=0.998)$. 


\section{Discussion}

Similarities in cognitive processes have been suggested between the creation and perception of art (Martindale, 2001). However, research has not been conducted directly examining the artist's aesthetic and art-making experience, although these relationships are suggested in current art-making models (Kozbelt, 2017; Mace \& Ward, 2002). Here, we investigate the experience of the artist prior to considering both the perceiver and artist relationships suggested in Tinio's mirror model of art. To date studies have only made indirect conclusions suggesting that there are similarities between preference and production (Taylor \& Eisenman, 1964; Boyatzis \& Eades, 1999), but here we gathered aesthetic and drawing preferences from both artists and non-artists to directly probe these relationships. Moreover, in order to explore the formation of aesthetic and drawing preference we recorded gaze behaviour examining the cognitive processes during perception (Free-viewing task) and of aesthetic and drawing preference to make conclusions on the relationships between aesthetic, drawing preferences and the formation of these judgements.

\section{Aesthetic and Drawing Relationship}

Drawing preference is found to be associated to aesthetic preference regardless of expertise supporting that a relationship exists between preference and production. We can conclude that the more pleasing an image is found to be the greater the preference is to draw

it. Over the next two sections we look further into the relationship between aesthetic and drawing preference by examining how preferences (aesthetic and drawing) relate to gaze when both free-viewing and making a drawing preference. 
560

561

562

563

564

565

566

567

568

569

570

571

572

573

574

575

576

577

578

579

580

581

582

583

584

\section{Free-viewing Task}

When non-artist and artist participants freely viewed pairs of stimuli we find aesthetically preferred images to be fixated on for longer periods of time, more often, fixated first and more on the image the more they prefer it. This supports previous research that suggests gaze is influenced by preference (Shimojo, Simion, Shimojo \& Scheier, 2003; Holmes \& Zanker, 2012). When we re-categorised free-viewing trials by drawing preference differences were found due to expertise with only artists' gaze being influenced by drawing preference. They fixated for longer on the image they preferred to draw, made more fixations and fixated on these more at the earliest opportunity. However, both artists and non- artists fixated more on the image they preferred to draw the more they desired to draw it. These differences between expertise may reflect previous reports of experienced artists being more deeply engaged (e.g., longer fixation durations) with the stimuli and the creative process (Nodine, Locher \& Krupinski, 1993; Tinio, 2013). When viewing art, artists may be interested in understanding the processes required to create the artwork and may observe and analyse images as a medium that can be reproduced (Pitman \& Hirzy, 2010). Artists may consider drawing preferences at this stage of viewing an image as they consider more about the artist behind the production. It has been suggested, in regards to paintings, that artists visualise more of the underdrawings whereas non-artists cannot visualise beyond the surface features (Chatterjee \& Vartanian, 2016). This suggests that the observation of art is not a passive process, particularly for an artist. Observing art results in similar experiences when both producing and appreciating art (Dewey, 1934; Tinio, 2013).

\section{Drawing Choice Task}

When a drawing preference was being made we find similar gaze patterns compared to free-viewing. This supports the suggestion that similar cognitive processes are involved in 
both the perception and creation of art (Martindale, 2001). Aesthetically preferred stimuli and those preferred for drawing were fixated on more, for longer, at the first opportunity, lastly, for longer before making a drawing preference and was fixated on more the more the image was preferred (aesthetic and drawing). These results further support that gaze is influenced by preference and reflects choice (Holmes \& Zanker, 2012; Shimojo, Simion, Shimojo \& Scheier, 2003; Glaholt, Wu \& Reingold, 2009).

During this task, stimuli were only viewed for a short period of time before a drawing preference was made supporting that this choice is made rapidly (Groenendijk, Janssen, Rijlaarsdam \& van den Bergh, 2013), in fact we find that artists first fixated their drawing preference more quickly (first saccade latency) whereas non-artists first fixated images less preferred for drawing more quickly. Differences here may be due to gaze gradually shifting towards the preferred choice (Shimojo, Simion, Shimojo \& Scheier, 2003); non-artists may not consider which image they would draw at this early stage. However, more first fixations were made to images preferred and those preferred for drawing regardless of expertise. Nevertheless, artists may be more aware of choices they will make as they consider the artmaking process more and were found to fixate more on what they would prefer to draw when free-viewing stimuli.

\section{Limitations and Future Directions}

In an attempt to allow both non-artists and artists to realistically be able to produce the stimuli, geometric shapes were used here rather than artworks. The use of abstract geometric shapes can also be suggested to be more reflective of the decisions made in the initial stages of art-making avoiding features of artworks that develop in later stages such as the addition of colour and texture. However, geometric shapes may be considered to be relatively far removed from the common sources of inspiration upon which art is created. To 
610

611

612

613

614

615

616

617

618

619

620

621

622

623

624

625

626

627

628

629

630

631

632

633

634

(3)

address this, the approach adopted here can be further developed by the use of stimuli such as photographs of real world scenes as would be used in landscape art. These can be used to form the basis of drawing decisions. This research can also be further extended to consider expert artists, particularly those with specific expertise in drawing. Artists were involved in the current study; however it has been reported that art students verbalise and acknowledge a lack of skill in drawing (McManus et al., 2010). Therefore, a useful next step in this area of research would be to replicate this study with other groups of art experts and other forms of art.

It is important to examine how the artists' own experience directs art-making decisions, which has been explored here. However, when we consider the relationship between aesthetic and drawing preference we can also consider a deeper experience of artmaking. Future research will examine the relationships between aesthetic and drawing experiences when making art at different stages of the process.

\section{Conclusion}

An association between aesthetic and drawing preferences was found, drawing preference scores increased with increasing aesthetic ratings regardless of expertise. Gaze behaviour when free-viewing reflects behaviour when making a drawing preference as gaze appears to be directed by the images aesthetically preferred during both tasks. For artists, their gaze when free-viewing was also influenced by images preferred for drawing. This suggests that a more fluid relationship exists for artists between images aesthetically preferred and those preferred for drawing. We suggest that during initial stages of art-making the aesthetic judgements of ideas are an important component in their selection. A strong relationship between the two was found with support from gaze behaviour. Here, we focus on the experiences of just the artist, but further studies are required to explore the artist in 
635 relation to the perceiver of the final product. Such research enables a greater understanding of 636 this interaction where we can explore the artist and their creation process in conjunction with 637 the perceiver and their aesthetic experience (Tinio, 2013; Vartanian, 2014). 


\section{References}

640 Bates, D., Maechler M., Bolker B., \& Walker S. (2014). lme4: Linear mixed-effects models 641 using Eigen and S4. R package version 1.1-7. http://CRAN.R-project.org/package=lme4.

642 Boyatzis, C. J., \& Eades, J. (1999). Gender differences in preschoolers' and kindergartners' 643 artistic production and preference. Sex Roles, 41(7-8), 627-638. 644 https://doi:10.1023/A:1018855707332

645 Calabrese, L., \& Marucci, F. S. (2006). The influence of expertise level on the visuo-spatial 646 ability: differences between experts and novices in imagery and drawing abilities. Cognitive 647 Processing, 7(1), 118-120. https://doi:10.1007/s10339-006-0094-2

648 Chatterjee, A., \& Vartanian, O. (2016). Neuroscience of aesthetics. Annals of the New York 649 Academy of Sciences, 1369(1), 172-194. http://doi: 10.1111/nyas.13035

650 Chen, C., Kasof, J., Himsel, A. J., Greenberger, E., Dong, Q., \& Xue, G. (2002). Creativity in 651 Drawings of Geometric Shapes A Cross-Cultural Examination with the Consensual 652 Assessment Technique. Journal of Cross-Cultural Psychology,33(2), 171-187. 653 http://doi: 10.1177/0022022102033002004

654 Chen, N., Tanaka, K., Matsuyoshi, D., \& Watanabe, K. (2016). Cross preferences for colors 655 and shapes. Color Research \& Application, 41(2), 188-195. http://doi: 10.1002/col.21958

656 Dewey, J. (1934). Having an experience, in Art as experience, 36-59. New York: Penguin.

657 Eisenman, R. (1968). Semantic differential ratings of polygons varying in complexity658 simplicity and symmetry-asymmetry. Perceptual and Motor Skills, 26(3c), 1243-1248. 659 http://dx.doi.org/10.2466/pms.1968.26.3c.1243 
660

661

662

663

664

665

666

667

668

669

670

671

672

673

674

675

676

677

678

679

680

Eisenman, R., \& Gellens, H. K. (1968). Preferences for complexity-simplicity and symmetryasymmetry. Perceptual

and motor

skills, 26(3),

888-890.

http://dx.doi.org/10.2466/pms.1968.26.3.888

Gartus, A., \& Leder, H. (2013). The small step toward asymmetry: aesthetic judgment of broken symmetries. i-Perception, 4(5), 361-364. http://doi: 10.1068/i0588sas

Glaholt, M. G., Wu, M. C., \& Reingold, E. M. (2009). Predicting preference from fixations. PsychNology

Journal, 7(2),

141-158.

https://pdfs.semanticscholar.org/3666/f7eb9d5e43f3e3dd7977d18dcb36550d47ab.pdf

Glazek, K. (2012). Visual and motor processing in visual artists: Implications for cognitive and neural mechanisms. Psychology of Aesthetics, Creativity, and the Arts, 6(2), 155-167. http://dx.doi.org/10.1037/a0025184

Gombrich, E. H. (1995). The story of art (Vol. 12). London: Phaidon.

Groenendijk, T., Janssen, T., Rijlaarsdam, G., \& van den Bergh, H. (2013). Learning to be creative. The effects of observational learning on students' design products and processes. Learning

and Instruction, 28,

$35-47$. http://dx.doi.org/10.1016/j.learninstruc.2013.05.001

Guggenheim, J., \& Whitfield, T. W. A. (1989). Fechner's method of production: An application to aesthetics. Perceptual and Motor Skills, 68(3c), 1330-1330. http://doi: 10.2466/pms.1989.68.3c.1330

Holmes, T., \& Zanker, J. M. (2012). Using an oculomotor signature as an indicator of aesthetic preference. $i$-Perception, 3(7), 426-439. http://doi:10.1068/i0448aap 
681 Humphrey, D. (1997). Preferences in symmetries and symmetries in drawings: Asymmetries 682 between ages and sexes. Empirical Studies of the Arts, 15(1), 41-60.

683 http://doi:10.2190/DF5N-HGFB-MVPK-U34D

684

Jacobsen, T., Schubotz, R. I., Höfel, L., \& Cramon, D. Y. V. (2006). Brain correlates of

685 aesthetic judgment of beauty. Neuroimage, 29(1), 276-285. http://doi:10.1016/j.neuroimage.2005.07.010

687 Kay, S. (1991). The figural problem solving and problem finding of professional and 688 semiprofessional artists and nonartists. Creativity Research Journal, 4(3), 233-252. 689 http://doi:10.1080/10400419109534396

690

Kozbelt, A. (2001). Artists as experts in visual cognition. Visual Cognition, 8 (6), 705-723.

691 http://doi: 10.1080/13506280042000090

692

Kozbelt, A. (2017). Tensions in naturalistic, evolutionary explanations of aesthetic reception 693 and production. New Ideas in Psychology (In press).

694 https://doi.org/10.1016/j.newideapsych.2017.03.006

695 Kozbelt, A., Seidel, A., ElBassiouny, A., Mark, Y., \& Owen, D. R. (2010). Visual selection 696 contributes to artists' advantages in realistic drawing. Psychology of Aesthetics, Creativity, 697 and the Arts, 4(2), 93-102. http://dx.doi.org/10.1037/a0017657

698 Kristjanson, A. F., Antes, J. R., \& Kristjanson, A. K. (1989). Eye movement analysis of 699 artists and nonartists viewing paintings. Visual Arts Research, 21-30. 700 http://www.jstor.org/stable/20715702

701 Leder, H. (2001). Determinants of preference: When do we like what we know?. Empirical 702 Studies of the Arts, 19(2), 201-211. http://doi:10.2190/5TAE-E5CV-XJAL-3885 
703

704

705

706

707

708

709

710

711

712

713

714

715

716

717

718

719

720

721

722

723

724

725

Leder, H., Belke, B., Oeberst, A., \& Augustin, D. (2004). A model of aesthetic appreciation and aesthetic judgments. British journal of psychology,95(4), 489-508. http:// doi:10.1348/0007126042369811

Leder, H., Tinio, P. P., Fuchs, I. M., \& Bohrn, I. (2010). When attractiveness demands longer looks: The effects of situation and gender. The Quarterly Journal of Experimental Psychology, 63(9), 1858-1871. http://doi:10.1080/17470211003605142

Locher, P., Krupinski, E. A., Mello-Thoms, C., \& Nodine, C. F. (2007). Visual interest in pictorial art during an aesthetic experience. Spatial Vision,21(1), 55-77. http://doi:0.1163/156856807782753868

Mace, M. A., \& Ward, T. (2002). Modeling the creative process: A grounded theory analysis of creativity in the domain of art making. Creativity Research Journal, 14(2), 179-192. http://doi:10.1207/S15326934CRJ1402_5

Martindale, C. (2001). How does the brain compute aesthetic preference. The General Psychologist, 36(2), 25-35.

McManus, I. C., Chamberlain, R., Loo, P. W., Rankin, Q., Riley, H., \& Brunswick, N. (2010). Art students who cannot draw: Exploring the relations between drawing ability, visual memory, accuracy of copying, and dyslexia. Psychology of Aesthetics, Creativity, and the Arts, 4(1), 18-30. http://dx.doi.org/10.1037/a0017335

McWhinnie, H. J. (1971). A review of selected aspects of empirical aesthetics III. Journal of Aesthetic Education, 115-126. http://doi:10.2307/3331624

Miall, R. C., \& Tchalenko, J. (2001). A painter's eye movements: A study of eye and hand movement during portrait drawing. Leonardo, 34(1), $35-40$. http://doi:10.1162/002409401300052488 
Nodine, C. F., Locher, P. J., \& Krupinski, E. A. (1993). The role of formal art training on perception and aesthetic judgment of art compositions. Leonardo, 219-227. http://doi:10.2307/1575815

Park, J., Shimojo, E., \& Shimojo, S. (2010). Roles of familiarity and novelty in visual preference judgments are segregated across object categories. Proceedings of the National Academy of Sciences, 107(33), 14552-14555. http://doi:10.1073/pnas.1004374107

Pihko, E., Virtanen, A., Saarinen, V. M., Pannasch, S., Hirvenkari, L., Tossavainen, T., Haapala., \& Hari, R. (2011). Experiencing Art: The Influence of Expertise and Painting $\begin{array}{lllll}\text { Abstraction } & \text { Level. Frontiers } \quad \text { in } \quad \text { Human } & \text { Neuroscience, 5, } & 94 .\end{array}$ https://doi.org/10.3389/fnhum.2011.00094

Pitman, B., \& Hirzy, E. C. (2010). Ignite the power of art: Advancing visitor engagement in museums. Dallas Museum of art. http://www.creatingquality.org/Portals/1/DNNArticleFiles/634684617231136642Ignite\%20th e\%20Power\%20of\%20Art.pdf

Plumhoff, J., \& Schrillo, J. (2009). Mondrian, eye movements, and the oblique effect. Perception, 38, 719-732. http://doi:10.1068/p6160

Reber, R., Schwarz, N., \& Winkielman, P. (2004). Processing fluency and aesthetic pleasure: is beauty in the perceiver's processing experience? Personality and Social Psychology Review, 8(4), 364-382. http:// doi: 10.1207/s15327957pspr0804_3

Russell, P. A., \& George, D. A. (1990). Relationships between aesthetic response scales applied to paintings. Empirical Studies of the Arts, 8(1), 15-30. https://doi.org/10.2190/AU1R-6UXE-T14R-04WQ 
Sapp, D. D. (1995). Creative Problem-Solving in Art: A Model for Idea Inception and Image Development. The journal of creative behavior, 29(3), 173-185. http:// doi: 10.1002/j.21626057.1995.tb00747.x

Shimojo, S., Simion, C., Shimojo, E., \& Scheier, C. (2003). Gaze bias both reflects and influences preference. Nature neuroscience, 6(12), 1317-1322. http:// doi:10.1038/nn1150

Snijders, T. A. B., \& Bosker, R. J. (2012). Discrete dependent variables. Multilevel analysis: an introduction to basic and advanced multilevel modeling, 304-307.

Taylor, R. E., \& Eisenman, R. (1964). Perception and production of complexity by creative art students. The Journal of Psychology, 57(1), 239-242. http://doi:10.1080/00223980.1964.9916693

Tinio, P. P. (2013). From artistic creation to aesthetic reception: The mirror model of art. Psychology of Aesthetics, Creativity, and the Arts, 7(3), 265-275. http://dx.doi.org/10.1037/a0030872

Tinio, P. P., \& Leder, H. (2009). Just how stable are stable aesthetic features? Symmetry, complexity, and the jaws of massive familiarization. Acta Psychologica, 130(3), 241-250. http://doi:10.1016/j.actpsy.2009.01.001

Vartanian, O. (2014). Empirical aesthetics: hindsight and foresight. In P.P. Tinio \& J. K. Smith, The Cambridge Handbook of the Psychology of Aesthetic and the Arts (pp.6-34). Cambridge: Cambridge University Press.

Vogt, S., \& Magnussen, S. (2007). Expertise in pictorial perception: eye-movement patterns and visual memory in artists and laymen. Perception, 36(1), 91-100. http://doi:10.1068/p5262 
769 Washburn, D., \& Humphrey, D. (2001). Symmetries in the mind: Production, perception, and 770 preference for seven one-dimensional patterns. Visual Arts Research, 57-68.

771 http://www.jstor.org/stable/20716037

772 Willis, J., \& Todorov, A. (2006). First impressions making up your mind after a 100-ms

773 $\begin{array}{llll}\text { exposure } & \text { to } & \text { a } & \text { face. Psychological }\end{array}$

774 http://journals.sagepub.com/doi/abs/10.1111/j.1467-9280.2006.01750.x

775 Winston, A. S., \& Cupchik, G. C. (1992). The evaluation of high art and popular art by naive 776 and experienced viewers. Visual Arts Research, 1-14. http://www.jstor.org/stable/20715763

777 Zeki, S., \& Nash, J. (1999). Inner vision: An exploration of art and the brain (Vol. 415).

778 Oxford: Oxford University Press. 